\title{
AN INVESTIGATION INTO THE INCIDENCE OF HERNIA IN CHILDREN.
}

\author{
BY \\ DONALD PATERSON, M.B., M.R.C.P., Out-Patient Physician, \\ and
}

GEORGE M. GRAY, M.B., Ch.B., F.R.C.S.E., Surgical Registrar, From the Hospital for Sick Children, Gt. Ormond Street, London.

Statistics from the British Isles on the incidence of hernia on a large scale are few. Certain facts have been stated and textbooks have repeated them without confirmation. To verify or impugn the accepted figures we have undertaken to investigate 1018 cases of hernia presenting themselves at the Out-Patient Department of the Hospital for Sick Children, Great Ormond Street. The period covered includes the years 1919, 1921, 1922, 1923, and 1924 ; and concerns the children up to the age of three years presenting themselves with inguinal hernia during this period. As regards umbilical hernia all cases during this period up to the age of 12 years were investigated.

Incidence of Hernia in Children of the Hospital Class. The number of new out-patients during the five years was 130,243 , and of these 1018 were suffering from hernia of some variety, that is, an incidence of $0.8 \%$. The sex incidence showed 838 males $(79 \%)$ and 180 females $(21 \%)$.

Inguinal Hernia. Out of 1018 cases there were 773 simple inguinal herniæ. 696 cases were males and 77 were females, that is, $90 \%$ were males and $10 \%$ females.

Operations and Recurrences. Out of the 773 inguinal herniæ, 564 were operated upon, with 4 recurrences. This is a proportion of $0.7 \%$. Of the 209 cases which were not operated upon, in 185 the hernia had apparently spontaneously disappeared, while in $\mathbf{2 4}$ the hernia was still present, but not operated upon for some special reason of the parents or the condition of the child.

Incidence of Spontaneous Cure of Inguinal Hernia. Out of the total of 773 inguinal herniæ investigated, 185 disappeared spontaneously. This is $\mathbf{2 4} \%$ or one quarter did not require operation.

The chances of a spontaneous disappearance of an inguinal hernia would appear to be better in females than in males, since in $37 \%$ of females but only in $22 \%$ of males did this occur.

That these figures represent only apparent cures must be emphasized; as in contrast to umbilical hernia where one can by a truss or pad invaginate and thereby obliterate the sac, thus being certain of cure, in inguinal hernia the word " cure" merely signified in many cases a fibrosis of the neck of the sac, a potential hernial sac still existing. It may be that from these apparent cures arises that class of case in which following on some unusual exertion, a scrotal hernia suddenly develops in a voung adult.

Age at which Spontaneous Disappearance Occurred. As far as could be ascertained the inguinal herniæ disappeared usually before the age of one year, but in some the hernia recurred at intervals up to the age of three years. 
Varieties of Inguinal Hernioe. In the total number of 773 cases of simple inguinal hernia, the proportions were :-right, 477 or $62 \%$; left, 155 or $20 \%$; double, 141 or $18 \%$.

In females, the preponderance of the right-sided variety is not so marked, the proportions being :-right, 35 cases or $45 \%$; left, 27 cases or $35 \%$; double, 15 or $20 \%$.

The disappearance rate in the three varieties is remarkably constant, being right $24 \%$; left $25 \%$; double $23 \%$; which gives the average figure $24 \%$ mentioned above. It will thus be seen that no one variety of inguinal hernia is more prone to disappear than another.

Strangulated Hernice. Of the in-patient operation returns for these five years the total of herniæ designated strangulated was eight, but in none of these was. resection of bowel necessary. These cases were all under two years of age, the youngest being nine months old.

Femoral Hernia. No case of femoral hernia was found. As our investigation was confined to children of three and under, it was unlikely that such a variety would be found, since of five cases occurring in the hospital records during these five years, the youngest was five years of age and it is doubtful if this form of hernia can be considered a congenital manifestation.

Umbilical Hernia. Of the 1018 cases investigated 214 were simple umbilical. herniæ. Of these 214 cases there were 112 males $(53 \%)$ and 102 females $(47 \%)$. Umbilical, in contrast with inguinal hernia, appears therefore to be about equal in the two sexes.

Incidence of Spontaneous Cure of Umbilical Hernia. Of these 214 cases, 46 were operated upon, 101 disappeared spontaneously and 67 were for one reason or another not operated upon. This implies that half the cases suffering from umbilical hernia are cured spontaneously and do not require operation, under the age of 12 years. The sex incidence of the disappearance rate, was roughly equal in the two sexes.

In a large proportion of those cases in which the umbilical hernia still existed it was claimed that the hernia had become much smaller.

Combined Umbilical and Inguinal Hernice. Of the 1018 cases there was a combined umbilical and inguinal hernia in 31 cases. Of these, 30 were in males and one in a female.

Incidence of Spontaneous Cure of Combined Umbilical and Inguinal Hernice. Of the 31 cases there was a spontaneous disappearance of both herniæ in 10 cases, or one-third, and the remainder were operated upon successfully.

\section{Discussion.}

There seems to be a general agreement as to the sex incidence in hernia, but on various other points there is a wide discrepancy of opinion and fact.

Inguinal Hernia. Fraser $\left(^{1}\right)$ states that of 1000 cases investigated, 906 $(90 \%)$ were males, and $94(10 \%)$ were females. Of these 1000 cases, $619,(62 \%)$ were of the right inguinal, $244(24 \%)$, of the left inguinal, and 107, $(11 \%)$ of the double inguinal variety, while $(303 \%)$ were not named. He suggests that the explanation of the greater proportion of right than of left 
herniæ would appear to be that the right processus vaginalis closes at a slightly later date than the left. Regarding the time for operation he thinks that operation should be undertaken

(1) between the third and sixth months; or

(2) at the end of the second year; or

(3) immediately before the child goes to school;

and that a circumcision should be done before the operation takes place if phimosis is present. Fraser further ventures the sweeping statement that no hope need be entertained of a natural cure after the age of three months.

Examining our figures, we make the total proportion of the incidence of herniæ in males and females as four to one. Fraser (p. 768) states that the proportional incidence of herniæ in males and females is about 20 to 1 . Of English authors, McAdam Eccles $\left({ }^{2}\right)$ and Hutchison $\left({ }^{3}\right)$ give the proportions as 5 to 1 which agree with our figures. Kerley( $\left.{ }^{4}\right)$ makes general statements which bear out our results, but does not quote actual figures. Richter( ${ }^{5}$ ), quoting Macready $\left({ }^{6}\right)$, states that " of each 1000 persons ruptured, 175 are affected in the first year of their life," and quoting Coley $\left({ }^{7}\right)$ he says that "the ratio between the sexes is $75 \%$ males and $25 \%$ females for all types of herniæ." This agrees closely with our figures. He also quotes Ochsner $\left(^{8}\right)$ as stating that " in $73 \%$ of all children suffering from herniæ from birth to the 6th year, the herniæ must have disappeared before the age of 13."

It will be seen that the figures quoted by $\operatorname{Pybus}\left({ }^{9}\right)$ agree closely with our own. He says that in inguinal herniæ $89 \%$ are males and $11 \%$ females, that it is commonest on the right side $(59 \%), 26 \%$ being on the left side and $15 \%$ bilateral. He considers that operation should take place any time after six months of age.

The treatment of inguinal hernia at the Hospital for Sick Children is generally :-

1. Circumcision in all cases if there is any straining.

2. Application of a truss preferably of rubber, as a skein of wool is useless except in plump children with a bubonocele.

3. Operation after the age of 1 year as then shock, both surgical and anæsthetic, is better withstood and the child has cleaner habits.

While this is the routine treatment, it would seem from the above figures that too pessimistic a prognosis of cure should not be given if operation is refused.

Umbilical Hernia. Regarding umbilical hernia, Fraser ${ }^{\left({ }^{1}\right)}$ carefully differentiates between the uncommon congenital umbilical hernia and the common post-natal umbilical hernia. In the congenital type the contents of the peritoneum tend to herniate through the abdominal wall behind the prolapsed umbilical cord. He does not state the sex incidence in such cases. He debates the best treatment, and is of opinion that if occlusion can be guaranteed for a period of from 4 to 6 months, there is every prospect of a natural cure. He thinks that operation should not be performed upon children below the age of three years. 
Kerley( ${ }^{(4)}$ states that " of 2000 operations for hernia under 14 years of age at the Hospital for the Ruptured and Crippled only $1.3 \%$ were for umbilical hernix."

Holt( $\left.{ }^{10}\right)$ advises strapping for umbilical hernia and states that operation above the age of 7 years is rarely necessary.

\section{Conclusions.}

We would conclude therefore :-

1. That the incidence of hernia among the out-patients attending a children's hospital is below $1 \%$.

2 . That the sex incidence of all herniæ in children is at the rate of 4 males to each female.

3. That inguinal hernia is about four times as common as umbilical hernia, its sex incidence being 9 males to each female.

4. That the tendency to an apparent spontaneous cure is marked. In inguinal hernia a fourth of all cases apparently cure themselves. This tendency to spontaneous cure is higher in females $(37 \%)$ than in males $(22 \%)$.

5. That right inguinal hernia is present in $62 \%$, left in $20 \%$, and double in $18 \%$.

6. The sex incidence in umbilical hernia is equal, and about half the cases are cured spontaneously under the age of 12 .

For permission to investigate these cases our thanks are due to the Surgeons of The Hospital for Sick Children.

\section{REFERENCES.}

1. Fraser, J., The Surgery of Childhood, II. 768.

2. Eccles, W. McA. Hernia, 13.

3. Hutchinson, J. Hernia, 2.

4. Kerley, C. G. Practice of Pediatrics, 3rd Ed. 283.

5. Richter, Harry M. Abt's Pediatrics, III. 593.

6. Macready, J. Treatise on Ruptures, 300.

7. Coley, W. B., Keen's Surgery, IV, 22.

8. Ochsner, A. J., Am. Med. Ass. Chic., 1900, xxxv, 1593.

9. Pybus, F (.., Surgical Diseases of Children.

10. Holt, I. Emmett, Diseases of Infancy and Childhood, 7th Ed. 116. 